\title{
Editorial
}

International Archives of
Allergy
Immunology

\section{Is Asthma Control Really More Difficult to Achieve in the Elderly Patient?}

\author{
Louis-Philippe Boulet \\ Quebec Heart and Lung Institute, Laval University, Québec, Qué., Canada
}

Despite significant advances in our understanding of asthma and the development of new treatments and management strategies, this common condition too often remains uncontrolled $[1,2]$. This is particularly true for elderly asthmatic patients, who, compared to younger patients, show an increased asthma-related morbidity and mortality $[3,4]$. Although often confounded with other conditions such as chronic obstructive pulmonary disease (COPD) or cardiac problems, asthma can affect between 4.5 and $12.7 \%$ of the elderly population $[5,6]$.

With the increasing life expectation observed in most countries, there is a marked interest to know more about how aging could influence respiratory health [4-6]. Aging influences not only respiratory function but also the immune response to infectious agents and the environment $[7,8]$. It can also contribute to the modulation of pathological processes such as those associated with asthma or COPD, therefore influencing clinical features and treatment responses. In this regard, a specific phenotype of 'asthma in the elderly' is being increasingly characterized $[4,6]$. However, not only can the normal physiological changes associated with age contribute to make asthma more severe, many management deficiencies have also been documented in elderly asthmatic patients. These include poor recognition of symptoms, poor adherence to therapy and difficulties associated with alterations in intellectual functioning, particularly memory, in addition to hearing loss, coordination problems affecting inhaler technique as well as psychological (e.g. depression) and socioeconomical problems. The increased

\section{KARGER}

(c) 2014 S. Karger AG, Basel

$1018-2438 / 14 / 1653-0149 \$ 39.50 / 0$

E-Mail karger@karger.com

www.karger.com/iaa prevalence of comorbidities and sometimes the complex polypharmacy prescribed also contribute to poor asthma control and/or medication-associated side effects in this population.

In the past, elderly patients were usually excluded from studies on asthma, so there is an urgent need to look at the influence of age on the response to management strategies of this condition and at possible ways of reducing its burden. Multiple future research needs on this topic have been detailed in recent reports $[4,6]$.

In the study by Ponte et al. [9] recently published in this journal, 401 steroid-naïve patients, predominantly women and with mostly long-standing (particularly in the older patients), uncontrolled asthma, were followed up for 1 year. The authors conclude that older age at enrolment does not predict asthma control or emergency department (ED) visits at follow-up if asthma is treated properly, even when lung function is reduced. There was a notable median reduction of ED visits at follow-up $(98 \%)$ in the group of subjects $<55$ years of age and in those $>55$ years $(92 \% ; p=0.02)$, suggesting a marked effect of the proposed interventions. There was no significant difference between the 2 groups. Age did not predict symptom control, number of ED visits, hospital admissions or improvement in lung function at follow-up, and the intervention resulted in similar control and improvement in quality of life in both groups.

In the above study, older subjects had poorer lung function and less severe rhinitis at the last visit (i.e. after 1 year). The observation of a poorer lung function in old- 
er patients has been reported previously and it may reflect structural changes in the airways over time, particularly if asthma is uncontrolled $[4,6,10]$. However, despite poorer function, the study suggests that in older asthmatic patients who receive proper asthma management, particularly the regular use of inhaled corticosteroids (ICS), asthma control can be improved and acute care needs reduced [9].

Many factors could explain the marked improvement in asthma outcomes in both groups studied. It is important to note that there was much room for improvement, as the patients had uncontrolled asthma with frequent ED visits and even hospital admissions. Furthermore, all were offered free regular controller medication. Maintenance medication like ICS is underused in elderly patients. As seen in the Brazilian cohort, whatever the age of the patients, the provision of ICS should result in favourable clinical outcomes. Furthermore, adhesion to therapy is a common weakness of care, particularly in the elderly, so the relatively close follow-up offered during the study, i.e. 5 visits over a period of 1 year, favoured adherence to therapy $[11,12]$. Regular medical review is another factor that is considered to help maintain asthma control, in addition to education and the provision of an action plan for the management of asthma exacerbations [13]. It must also be noted that in the study by Ponte et al. [9], only patients with at least $80 \%$ adherence to medication were included in the analysis.

Although current guidelines suggest to prescribe an ICS as the initial treatment of asthma, in the present study, it included inhaled budesonide $(800 \mu \mathrm{g} /$ day $)$ and formoterol $(24 \mu \mathrm{g} /$ day $)$ plus an inhaled short-acting $\beta_{2}$ agonist on demand $[14,15]$. We have, however, little data on the best choice of initial treatment in older asthmatic patients. There is a need to explore whether ICS plus a long-acting $\beta_{2}$ agonist could provide additional benefits in this population, with the more severe airway obstruction observed and the more neutrophilic or mixed airway inflammatory phenotype [10].

Other factors like the documentation of comorbidities could also have influenced the asthma outcomes. Recognition of these conditions, particularly those affecting asthma control, is a key recommendation in current guidelines [14-16]. Of note is that in the study by Ponte et al. [9], the older subjects with asthma had few symptoms of rhinitis; this was possibly related to a lower prevalence of atopy.

With regard to the small difference in the outcomes reported, we should say that a wide range of care deficiencies observed in the elderly population was addressed, but also that the patients in the older group were not actually very old ( $>55$ years), with a more marked difference in patients $>70$ years being likely. The older patients had initially less ED visits than the younger ones. Nevertheless, this report stresses a need to offer this population a comprehensive adapted approach, taking into account the possible difficulties associated with asthma management in the elderly [17-19]. It also shows that, even in younger patients, such an approach is associated with an impressive improvement in their condition. We still need to still explore whether this is the case in much older patients, especially with the increasing percentage of this age group in the populations of many countries.

In conclusion, it is reassuring to see that despite asthma phenotypic changes in the elderly, adequate asthma management can be successful in markedly improving asthma control and reducing acute health care needs.

\section{References}

-1 Cazzoletti L, Marcon A, Janson C, Corsico A, Jarvis D, Pin I, Accordini S, Almar E, Bugiani M, Carolei A, Cerveri I, Duran-Tauleria E, Gislason D, Gulsvik A, Jõgi R, Marinoni A, Martínez-Moratalla J, Vermeire P, de Marco R; Therapy and Health Economics Group of the European Community Respiratory Health Survey: Asthma control in Europe: a realworld evaluation based on an international population-based study. J Allergy Clin Immunol 2007;20:1360-1367.

2 O'Byrne PM, Pedersen S, Schatz M, Thoren A, Ekholm E, Carlsson LG, Busse WW: The poorly explored impact of uncontrolled asthma. Chest 2013;143:511-523.
3 Moorman JE, Rudd RA, Johnson CA, King M, Minor P, Bailey C, Scalia MR, Akinbami LJ; Centers for Disease Control and Prevention (CDC): National surveillance for asthma United States, 1980-2004. MMWR Surveill Summ 2007;56:1-54.

-4 Hanania NA, King MJ, Braman SS, Saltoun C, Wise RA, Enright P, Falsey AR, Mathur SK, Ramsdell JW, Rogers L, Stempel DA, Lima JJ, Fish JE, Wilson SR, Boyd C, Patel KV, Irvin CG, Yawn BP, Halm EA, Wasserman SI, Sands MF, Ershler WB, Ledford DK: Asthma in Elderly workshop participants: Asthma in the elderly: current understanding and future research needs - a report of a National Institute on Aging (NIA) workshop. J Allergy Clin Immunol 2011;128(suppl 3):S4-S24. 
5 Braman SS: Growing old with asthma: what are the changes and challenges? Expert Rev Respir Med 2010:4:239-248.

-6 Yáñez A, Cho SH, Soriano JB, Rosenwasser LJ, Rodrigo GJ, Rabe KF, Peters S, Niimi A, Ledford DK, Katial R, Fabbri LM, Celedón JC, Canonica GW, Busse P, Boulet LP, BaenaCagnani CE, Hamid Q, Bachert C, Pawankar R, Holgate ST: Asthma in the elderly: what we know and what we have yet to know. World Allergy Organ J 2014;7:8.

7 Janssens JP, Pache JC, Nicod LP: Physiological changes in respiratory function associated with ageing. Eur Respir J 1999;13:197-205.

8 Sharma G, Goodwin J: Effect of aging on respiratory system physiology and immunology. Clin Interv Aging 2006;1:253-260.

-9 Ponte EV, Stelmach R, Franco R, SouzaMachado C, Souza-Machado A, Cruz AA: Age is not associated with hospital admission or uncontrolled symptoms of asthma if prop- er treatment is offered. Int Arch Allergy Immunol 2014;165:61-67.

10 Ducharme ME, Prince P, Hassan N, Nair P, Boulet LP: Expiratory flows and airway inflammation in elderly asthmatic patients. Respir Med 2011;105:1284-1289.

-11 Enright PL, McClelland RL, Newman AB, Gottlieb DJ, Lebowitz MD: Underdiagnosis and undertreatment of asthma in the elderly. Cardiovascular Health Study Research Group. Chest 1999;116:603-613.

$>12$ Boulet LP, Vervloet D, Magar Y, Foster JM: Adherence: the goal to control asthma. Clin Chest Med 2012;33:405-417.

13 Powell H, Gibson PG: Options for self-management education for adults with asthma. Cochrane Database Syst Rev 2003;1: CD004107.

14 Lougheed MD, Lemiere C, Dell SD, Ducharme FM, FitzGerald JM, Leigh R, Licskai C, Rowe BH, Bowie D, Becker A, Boulet LP; Ca- nadian Thoracic Society Asthma Committee: Canadian Thoracic Society Asthma Management Continuum - 2010 consensus summary for children six years of age and over, and adults. Can Respir J 2010;17:15-24.

15 Global Initiative on Asthma (GINA) 2014. http://www.ginasthma.com

16 Boulet LP, Boulay ME: Asthma-related comorbidities. Expert Rev Respir Med 2011;5: 377-393.

17 Gibson PG, McDonald VM, Marks GB: Asthma in older adults. Lancet 2010;376:803-813.

18 McDonald VM, Simpson JL, Higgins I, Gibson PG: Multidimensional assessment of older people with asthma and COPD: clinical management and health status. Age Ageing 2011;40:42-49.

19 Goeman D, Jenkins C, Crane M, Paul E, Douglass J: Educational intervention for older people with asthma: a randomised controlled trial. Patient Educ Couns 2013;93:586-595. 